\title{
Investigating the variation and non-stationarity in precipitation extremes based on the concept of event-based extreme precipitation
}

\author{
Dunxian She $^{\mathrm{a}, \mathrm{b}, *}$, Quanxi Shao ${ }^{\mathrm{c}, *}$, Jun Xia ${ }^{\mathrm{a}, \mathrm{b}}$, John A. Taylor ${ }^{\mathrm{d}}$, Yongyong Zhang ${ }^{\mathrm{e}}$, Liping Zhang ${ }^{\mathrm{a}, \mathrm{b}}$, \\ Xiang Zhang ${ }^{\mathrm{a}, \mathrm{b}}$, Lei Zou ${ }^{\mathrm{a}, \mathrm{b}}$ \\ a State Key Laboratory of Water Resources and Hydropower Engineering Science, Wuhan University, No. 8 Donghu South Road, Wuhan 430072, PR China \\ ${ }^{\mathrm{b}}$ Hubei Collaborative Innovation Center for Water Resources Security, Wuhan 430072, PR China \\ ' CSIRO Digital Productivity, Leeuwin Centre, 65 Brockway Road, Floreat, WA 6014, Australia \\ ${ }^{d}$ CSIRO Digital Productivity, GPO Box 664, Canberra, ACT 2601, Australia \\ ${ }^{\mathrm{e}}$ Key Laboratory of Water Cycle and Related Land Surface Processes, Institute of Geographic Sciences and Natural Resources Research, CAS, Beijing 100101, PR China
}

\section{A R T I C L E I N F O}

\section{Article history:}

Received 6 August 2015

Received in revised form 7 October 2015

Accepted 9 October 2015

Available online 23 October 2015

This manuscript was handled by Geoff

Syme, Editor-in-Chief

\section{Keywords:}

Event-based extreme precipitation

Generalized Pareto distribution

Non-stationary

Hanjiang River Basin

\begin{abstract}
A B S T R A C T
Extreme precipitations (EP) could induce a series of social, environmental and ecological problems. Traditional EP analysis usually investigated the characteristics based on a fixed time scale and therefore ignored the continuity of EP occurrence. As a result, a comprehensive assessment on the influence and consequence of the EP occurring during consecutive time periods were largely eliminated. On the other hand, the characteristics of EP, including variables such as frequency, intensity and extreme volume, were commonly defined without sufficient consideration of the local tolerance capacity (which can be represented by a threshold level of EP) and therefore would sometimes be inappropriate. In this study, we proposed a concept of event-based extreme precipitation (EEP) by considering the continuity of EP and defined the statistical variables for the characteristics of an EEP event by taking account of local tolerance capacity. An EEP was identified as a collection of precipitation data over the consecutive time period in which all the precipitation amounts are above the pre-defined threshold, and EEP events are separated by at least one time step (e.g., day or hour) with precipitation amount below the threshold. As a case study which in fact motivated our proposal, we investigated the changes and variations of EEP with the consideration of potential non-stationarity in the Hanjiang River Basin of China (HJRB) during the time period of 1960-2013. Results showed that the concept of EEP, which could reflect the impact of continuity of EP occurrence and mirror the differences of local tolerance capacity, was more appropriate than the traditional method in the EP analysis.
\end{abstract}

Crown Copyright @ 2015 Published by Elsevier B.V. All rights reserved.

\section{Introduction}

The analysis of extreme precipitation (EP) has received considerable attention, mainly due to its implications for hazard assessment and risk management (Easterling et al., 2000; Beguería et al., 2011). As shown by both observations and climate model simulations, EP increased under a warming climate (Zhai et al., 2005; Goswami et al., 2006; Mishra et al., 2012; Ali et al., 2014). The projections of precipitation patterns by the Intergovernmental Panel on Climate Change (IPCC) Fifth report, resulting from climate change, usually suggested that the intensity of EP would increase

\footnotetext{
* Corresponding authors at: State Key Laboratory of Water Resources and Hydropower Engineering Science, Wuhan University, No. 8 Donghu South Road, Wuhan 430072, PR China (D. She).

E-mail addresses: shedunxian@whu.edu.cn (D. She), Quanxi.Shao@csiro.au (Q. Shao).
}

with atmospheric temperature at a faster rate $\left(\sim 7 \%{ }^{\circ} \mathrm{C}^{-1}\right)$ than average precipitation $\left(1-3 \%{ }^{\circ} \mathrm{C}^{-1}\right)$ at the global scale (Stocker et al., 2013; Rajah et al., 2014).

A precipitation event is defined as an EP when its amount exceeds a certain threshold (Bell et al., 2004). The determination of threshold is a key factor in the generation of EP series. Du et al. (2013) grouped the methods of threshold determination into three categories: the fixed value method, the standard deviation method and the percentile-based method. In practice, the percentile-based method were widely used in many regions over the world because of its efficiency and simplicity (Bell et al., 2004; Wang and Zhou, 2005; Du et al., 2013). In most cases, the EP was based on the 90th (Gemmer et al., 2011), 95th (Bell et al., 2004; Zhai et al., 2005), 97.5th (Wang and Zhou, 2005) or 99th (Gemmer et al., 2011) percentiles of daily precipitation data, which represent moderate to extremely unusual events and were 


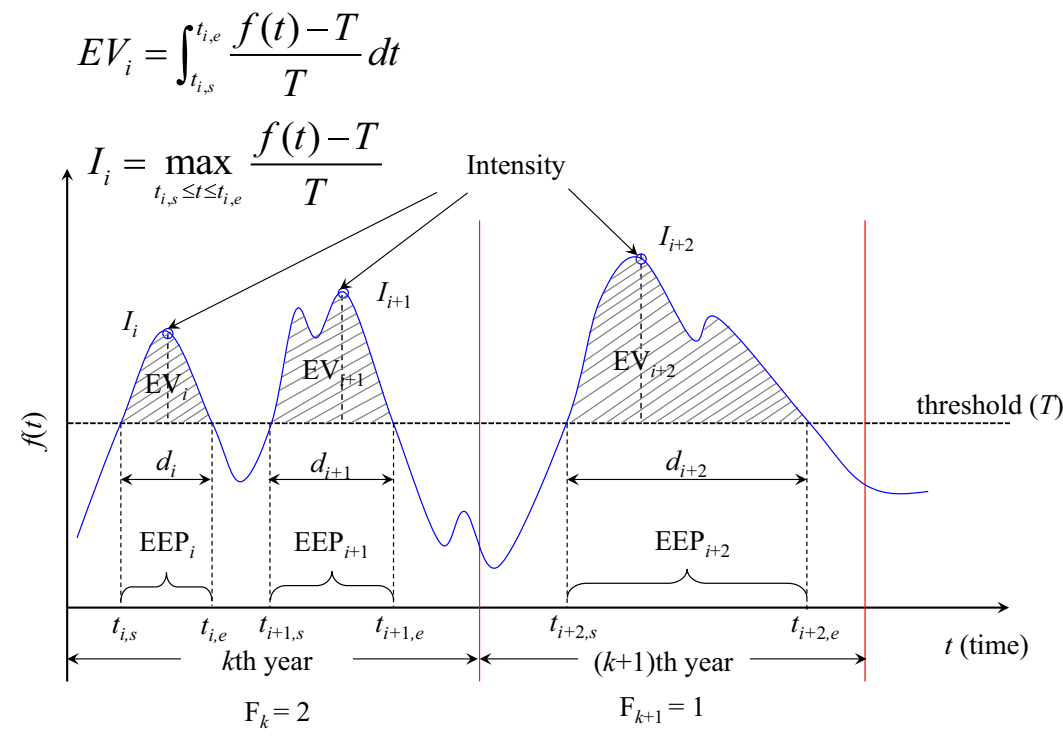

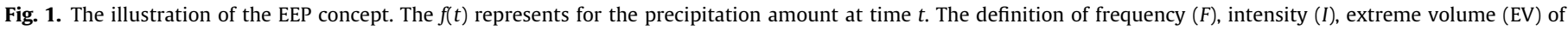
event-based extreme precipitation (EEP) events. (Note: $d_{i}$ represents the duration of a single EEP, which corresponds to the time interval of EEP event.)

demonstrated to be appropriate in various regions (Alexander et al., 2006; Ghosh et al., 2012; Vittal et al., 2013). Three indicators, i.e., frequency $(F)$, intensity $(I)$ and extreme volume $(E V)$, are often used to describe the characteristics and detect the trends of EP. Usually, frequency is defined as the number of EP per year, intensity is referred to the peak precipitation amount. However, Du et al. (2013) argued that the commonly used intensity definition would be inappropriate sometimes, and hence proposed a modified intensity index by considering the local tolerance capacity (i.e., threshold), which was defined as the value of the precipitation amount exceeding the threshold divided by the corresponding threshold. They expected that, by comparing the EP events with different thresholds and precipitation amount, the modified index was more suitable than the usually used one.

On the other hand, the continuity and duration of EP should also be addressed in the definition of the characteristics of EP. For example, consider two EP events with the same total precipitation amount under the threshold of $70 \mathrm{~mm}$ and assume that the first event has EP occurring in a single day with precipitation amount of $240 \mathrm{~mm}$ and the second event has EP occurring in three consecutive days with precipitation amount of $80 \mathrm{~mm}$ in each day. In general, the first event might cause a flash flood, while the second one may also induce a heavy flood through the cumulative runoff generation. In most studies, the EP was considered only on the single daily scale, and the event like the second one was commonly treated separately as three single EP events and, as a result, its impact might be neglected or weakened because the daily precipitation amounts are not so large when the continuity of EP occurrence is ignored. Vittal et al. (2013) defined the EP in term of clusters, i.e., a cluster of EP was identified as successive days when daily precipitation was above the respective threshold, and clusters were separated when there was at least a single day between them with precipitation amount below the threshold. However, the intensity and extreme volume in their study still did not consider the influence of local tolerance capacity and the volume is not sufficiently considered. Therefore, the characteristics of EP should be better defined with the consideration of the local tolerance capacity (i.e., threshold) and also the continuity of EP event period.

With respect to the frequency analysis for extreme characteristics, various distributions were used in modelling extreme hydroclimatological extreme series such as extreme value distributions
(Moberg and Jones, 2005; Alexander et al., 2006; Xia et al., 2011), Extended Burr XII distribution (Shao et al., 2004) and Pearson III distributions (Griffis and Stedinger, 2007). As the EEP was determined by a threshold, the generalized Pareto distribution, as a peak-over-threshold distribution, was selected in analyzing the EPP characteristics in the case study of this paper.

The stationarity, i.e. the statistical properties of a process not changing over time, was implicitly assumed in frequency analysis (Beguería et al., 2011). However, in the context of climate change, such stationarity would no longer hold and the results by traditional frequency analysis would become doubtful (Khaliq et al., 2006; El Adlouni et al., 2007). Therefore, the traditional frequency analysis under the stationarity assumption, which implies the absence of trends, shift and periodicities (Villarini et al., 2010), might not be appropriate to simulate the extreme series under a changing statistical characteristics (e.g., mean and variance) over time.

To deal with the underlying non-stationary effect, some studies made the distributional parameters to be time-dependent by using the time as a covariate (Kharin and Zwiers, 2005; Towler et al., 2010). However, the functional relationships between parameters and the time need to be specified as a priori, and such information might not be available or persistent over time due to the complexity of climate system (Kao and Ganguly, 2011; Ghosh et al., 2012). Alternatively, the distributional parameters were estimated separately for a series of $Y$-years moving window, rather than for the entire extreme series (Kao and Ganguly, 2011; Ghosh et al., 2012; Vittal et al., 2013). A choice of 30 years of window size was recommended by Kao and Ganguly (2011) considering that it was expected to smooth out the effects of most multi-decadal climate oscillators and providing more confidence for low frequency extremes (Kharin et al., 2007). This method has been proved to be an effective way to cope with the potential nonstationarity probably existed in the extreme series.

In this paper, we proposed the concept of event-based extreme precipitation (EEP) to eliminate the influence of local tolerance capacity (i.e., threshold) and simultaneously consider the continuity of EP occurrence in the EP analysis. The thresholds of EEP in each station were determined by the percentiles method. We would also define the characteristics of EEP (i.e. the variables of frequency, intensity and extreme volume) in this paper, and detect 

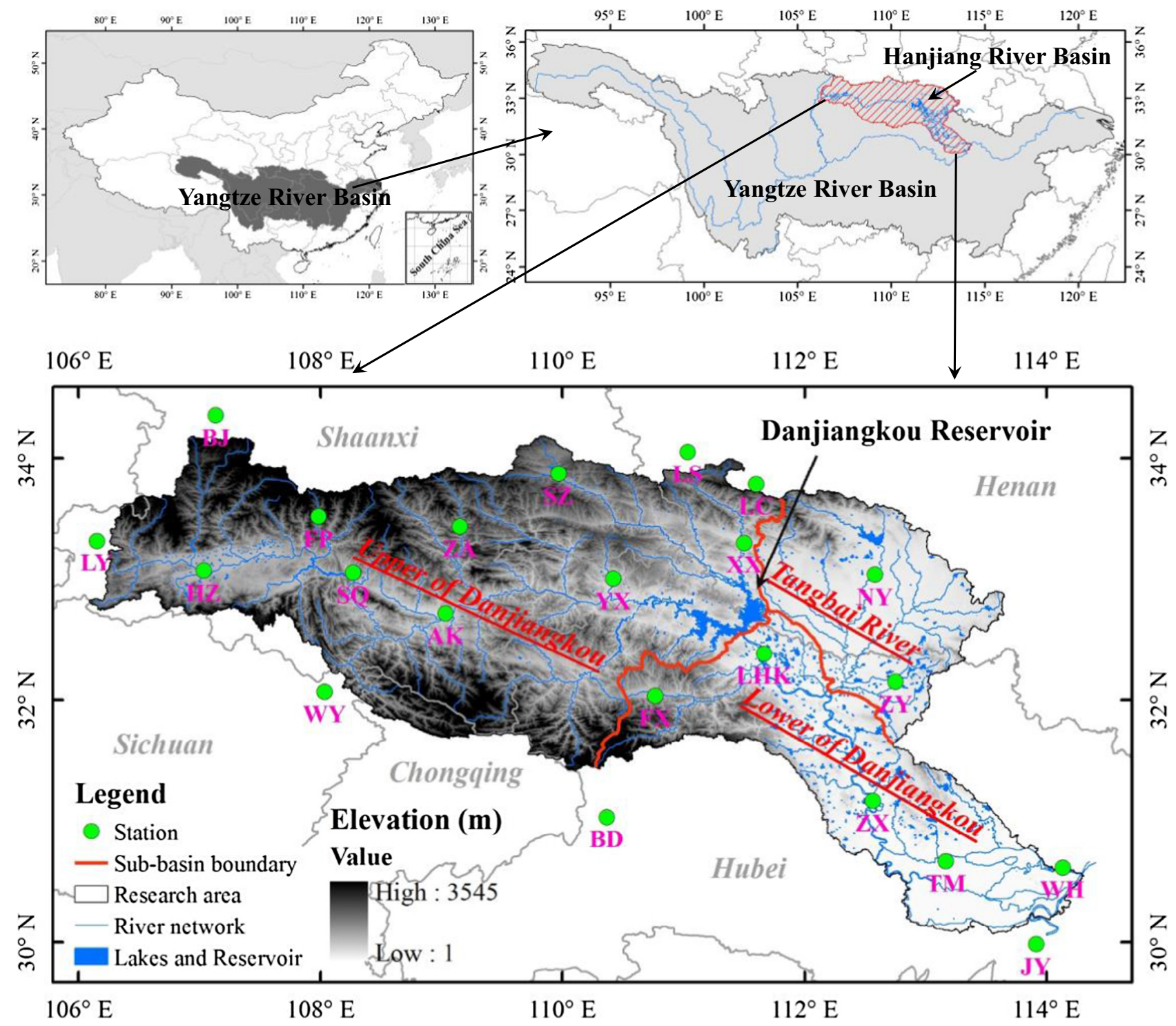

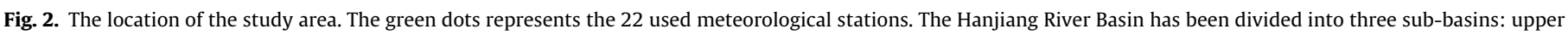

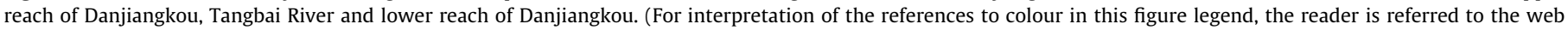
version of this article.)

the trends of these variables. The potential non-stationarity of EEP events would be specially considered, the Generalized Pareto Distribution (GPD) was chosen to fit characteristics of EEP (i.e., intensity and extreme volume), and the moving window method introduced by Kao and Ganguly (2011), Vittal et al. (2013) was employed to deal with the underlying non-stationarity of extreme series.

As a case study which in fact motivated our proposal, the Hanjiang River Basin of China (HJRB), which is the largest tributary of Yangtze River, was chosen as a case study. Many literatures have been documented to understand the changes in frequency, intensity of EP in many regions and basins of China (Yang et al., 2010; Xia et al., 2011; Zhang et al., 2012; Fu et al., 2013; Wang et al., 2013; Li et al., 2014), and the EP events were observed to be more frequent in the past several decades and were projected to increase in the frequency and intensity in most areas of China (Zhai et al., 2005; Zhang et al., 2006; Gemmer et al., 2011). However, previous studies mainly focused on the changes of precipitation on the monthly or annual scale in the area of our case study (Chen et al., 2007; Zhang et al., 2007; Ren et al., 2014), and little attention had been paid to the variations on the daily scale, especially for the
EP. Provided that the Danjiangkou Reservoir, which is located in the upper reach of HJRB, is the headwater source of the Chinese South-to-North Water Division Project (SNWDP) and that floods are frequently occurred in the middle and lower reach of HJRB, the changes of precipitation patterns and EP are closely related to the future development of this area and the SNWDP's operation. Therefore, the analysis of characteristics of EP in HJRB should be particularly investigated and assessed.

The paper is organized as follows. The definition of event-based extreme precipitation and its characteristics are given in Section 2. The method to deal with the non-stationarity will be also presented in this section. The area and data for the case study are briefly described in Section 3. Section 4 gives the results and some discussions, followed by summary and conclusions in Section 5 .

\section{Methodology}

\subsection{Event-based extreme precipitation and its characteristics}

In order to eliminate the impact of local tolerance capacity (i.e., threshold) and also consider the continuity of EP, we propose the 
Table 1

The detailed information of 22 used stations in HJRB.

\begin{tabular}{rllllll}
\hline No. & Name & Abbr. & Province & $\begin{array}{l}\text { Elevation } \\
(\mathrm{m})\end{array}$ & $\begin{array}{l}\text { Latitude } \\
(\mathrm{N})\end{array}$ & $\begin{array}{l}\text { Longitude } \\
(\mathrm{E})\end{array}$ \\
\hline 1 & Baoji & BJ & Shaanxi & 612.4 & 34.35 & 107.13 \\
2 & Lushi & LS & Henan & 568.8 & 34.05 & 111.03 \\
3 & Shangzhou & SZ & Shaanxi & 742.2 & 33.87 & 109.97 \\
4 & Luanchuan & LC & Henan & 750.3 & 33.78 & 111.60 \\
5 & Foping & FP & Shaanxi & 827.2 & 33.52 & 107.98 \\
6 & Zhen'an & ZA & Shaanxi & 693.7 & 33.43 & 109.15 \\
7 & Lveyang & LY & Shaanxi & 794.2 & 33.32 & 106.15 \\
8 & Xixia & XX & Henan & 250.3 & 33.30 & 111.50 \\
9 & Hanzhong & HZ & Shaanxi & 509.5 & 33.07 & 107.03 \\
10 & Shiquan & SQ & Shaanxi & 484.9 & 33.05 & 108.27 \\
11 & Nanyang & NY & Henan & 129.2 & 33.03 & 112.58 \\
12 & Yunxi & YX & Hubei & 249.1 & 33.00 & 110.42 \\
13 & Ankang & AK & Shaanxi & 290.8 & 32.72 & 109.03 \\
14 & Laohekou & LHK & Hubei & 90 & 32.38 & 111.67 \\
15 & Zaoyang & ZY & Hubei & 125.5 & 32.15 & 112.75 \\
16 & Wanyuan & WY & Sichuan & 674 & 32.07 & 108.03 \\
17 & Fangxian & FX & Hubei & 426.9 & 32.03 & 110.77 \\
18 & Zhongxiang & ZX & Hubei & 65.8 & 31.17 & 112.57 \\
19 & Badong & BD & Hubei & 334 & 31.03 & 110.37 \\
20 & Tianmen & TM & Hubei & 34.1 & 30.67 & 113.17 \\
21 & Wuhan & WH & Hubei & 23.1 & 30.62 & 114.13 \\
22 & Jiayu & JY & Hubei & 36 & 29.98 & 113.92 \\
& & & & & & \\
\hline
\end{tabular}

concept of event-based extreme precipitation (EEP), Fig. 1 depicts EEP concept and the process of extracting EEP from the data series. For a given precipitation series on daily or other time scale, a precipitation event can generally be determined as an EP when its amount exceeds a threshold level (i.e., $T$ in Fig. 1). However, a single EEP is defined as a collection of precipitation over the consecutive time period in which all the precipitation amounts are above the pre-defined threshold, and EEP events are separated by at least one time step (e.g., day or hour) with precipitation amount below the threshold (see the time periods covered by the shade area in Fig. 1). Therefore, an EEP might include several independent EP events and have different time span. The EEP events can be extracted from the precipitation series by identifying all the precipitation amounts over the pre-defined threshold and then grouping these precipitations by their continuity in time. Unlike the common understanding, the EEP events with duration of more than one time step widely exist even for daily data series. For example, the daily precipitation series at Wanyuan meteorological station in our case study during 1960-2013 had nine EEP events with duration of more than 2 days when the $97.5 \%$ percentile (i.e., $76.8 \mathrm{~mm} /$ day) was used as the threshold (e.g., the precipitation event from 31 August to 2 September 2003 had daily precipitation amount above $88.0 \mathrm{~mm}$ in each day).
After the EEP events are extracted, we can investigate their statistical characteristics from different aspects/dimensions. In this paper, we define three indicators, i.e., the frequency, intensity and extreme volume, to describe the characteristics of EEP events. The details are given as follow. The EEP frequency refers to the number of EEP events in one year. For an identified EEP event (EEP in Fig. 1) under a fixed threshold $(T)$, the EEP duration $\left(d_{i}\right)$ is defined as the interval between the starting $\left(t_{i, s}\right)$ and ending time $\left(t_{i, e}\right)$ of the EEP event and the intensity $\left(I_{i}\right)$ of $\mathrm{EEP}_{i}$ is defined as the maximum precipitation amount above the threshold divided by the corresponding threshold. Unlike the extreme volume (EV) used in previous studies where EV always corresponds to the total precipitation amount or the total amount exceeding the threshold of an EP event (Vittal et al., 2013) without considering the local tolerance capacity, in this study, EV is defined as the total precipitation amount exceeding the threshold divided by the threshold value. The formulations of the three indicators are given as:

$$
\left\{\begin{array}{l}
d_{i}=t_{i, e}-t_{i, s} \\
I_{i}=\max _{t_{i, s} \leqslant t \leqslant t_{i, e}} \frac{f(t)-T}{T} \\
\mathrm{EV}_{i}=\int_{t_{i, s}}^{t_{i, e}} \frac{f(t)-T}{T} d t
\end{array}\right.
$$

where $f(t)$ represents the precipitation series, and $t$ is the variable of time.

Moreover, different choices of threshold will generate different extreme series and thus will eventually influence the characteristics of EEP (such as frequency, intensity, and extreme volume). By taking account of the amounts and variation of historical precipitation series, we adopted the percentile-based method to determine the EEP threshold in the current study. More specifically, the threshold can be defined by the amount according to the corresponding percentile of the historical precipitation in rainy days. In this study, the rainy day is referred to the days receiving no less than $1 \mathrm{~mm}$ precipitation, which has been shown to generate more reliable estimates of extreme value models by eliminating trace measures of precipitation (Moberg and Jones, 2005; Alexander et al., 2006).

\subsection{Extreme value distribution}

Many extreme value distributions (EVD) are frequently used to model the extreme hydro-meteorological records. However, more and more studies found that the Generalized Pareto Distribution (GPD; see Pickands (1975)) could better simulate the Peak-overThreshold (POT) extreme series (Martins and Stedinger, 2001;

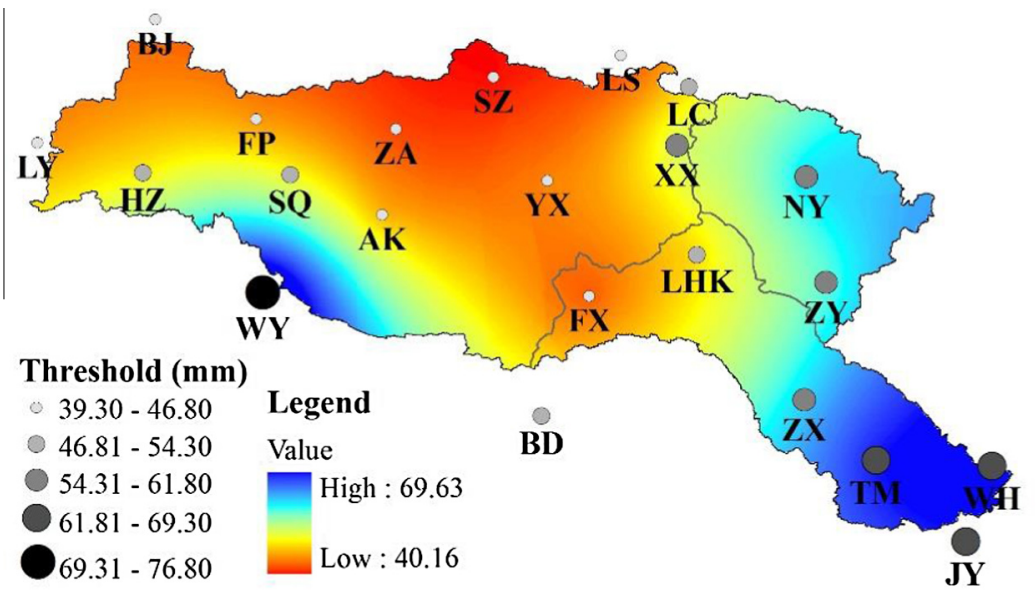

Fig. 3. The spatial distribution of EEP threshold in HJRB. 

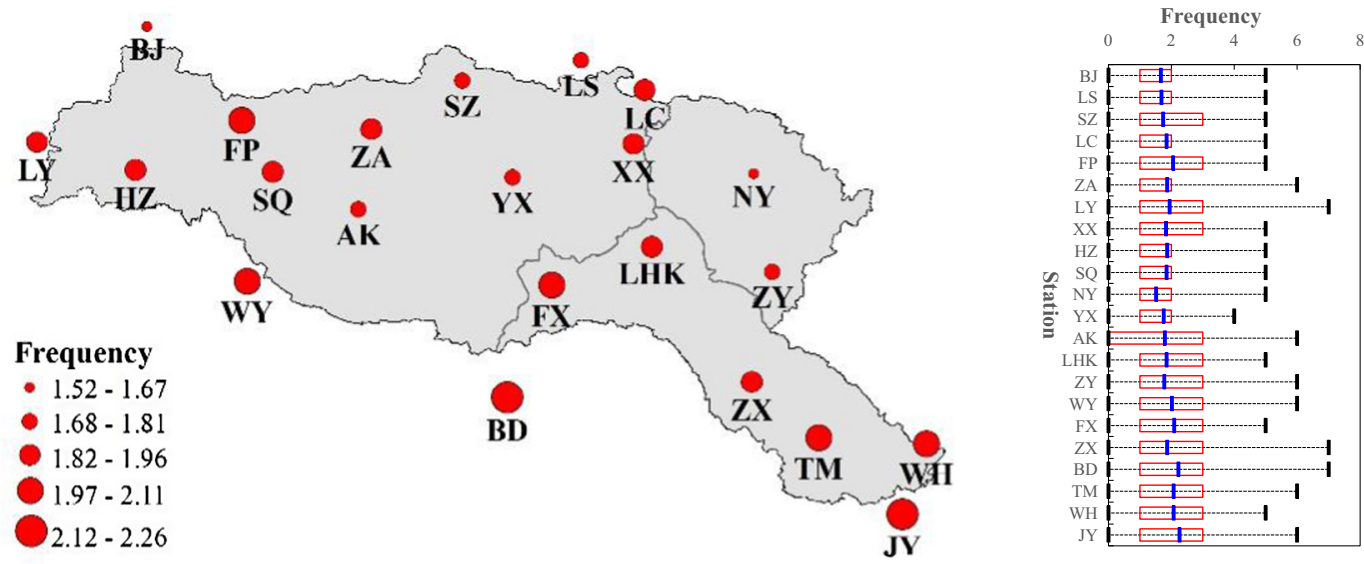

(a)
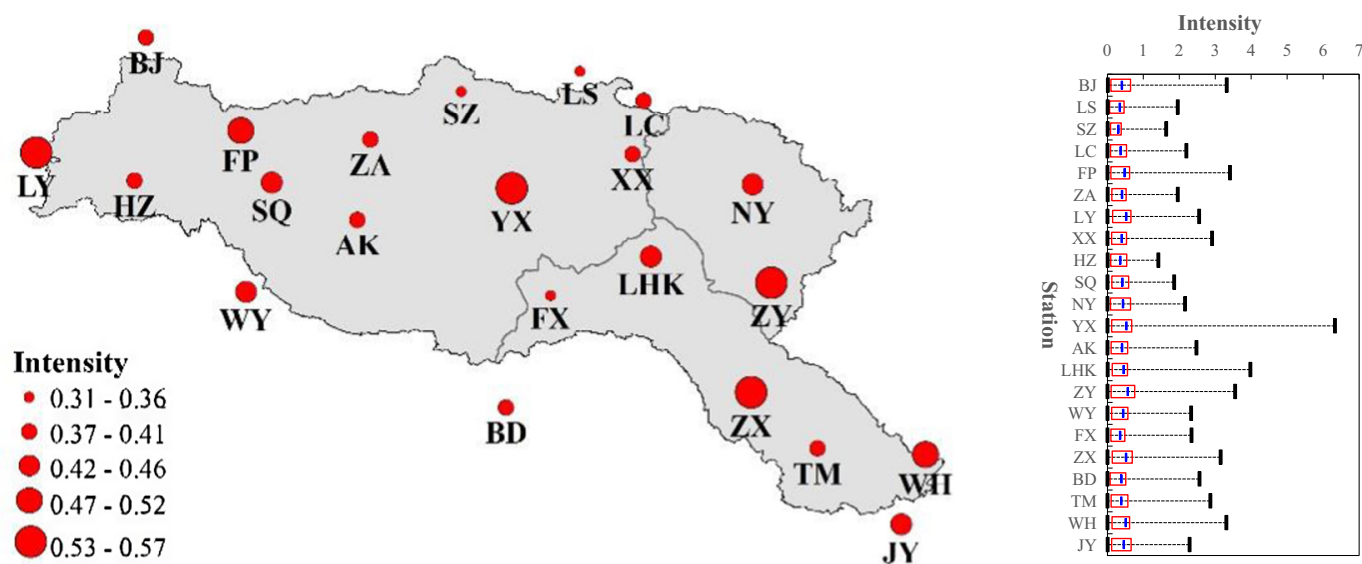

(b)
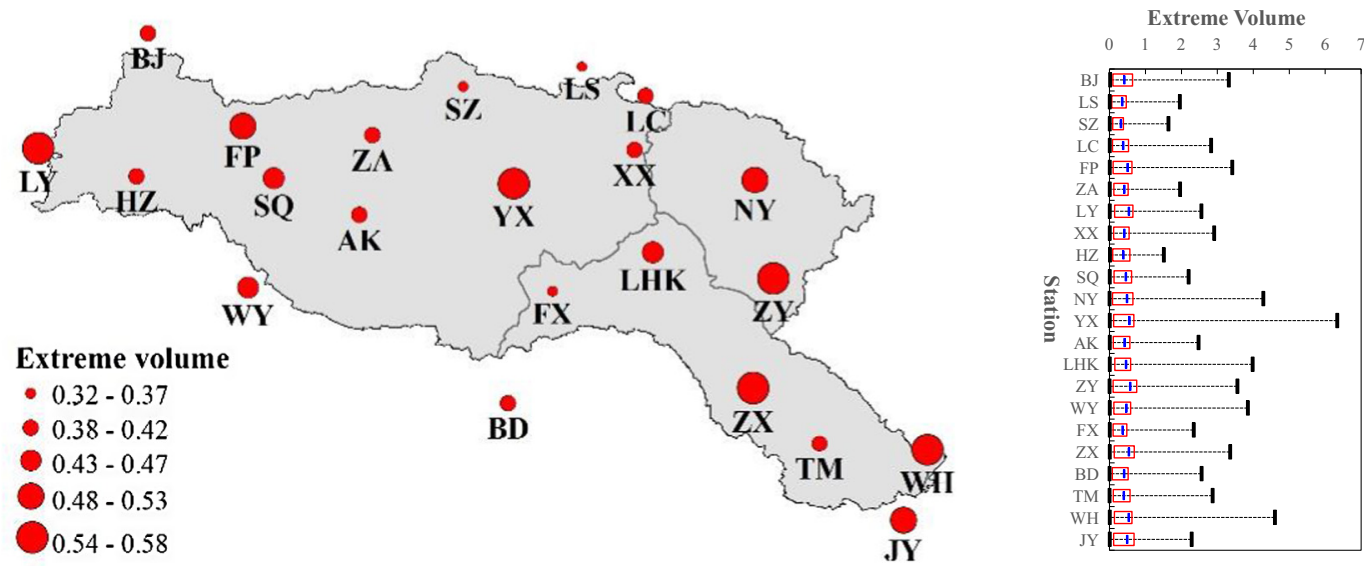

(c)

Fig. 4. The spatial distribution and boxplot of temporal mean of (a) frequency, (b) intensity and (c) extreme volume in HJRB.

Beguería, 2005; Xia et al., 2011; Bhunya et al., 2013; Naveau et al., 2014). Considering that the EEP events, in the current study, are defined by POT idea in term of quantiles, we employ GPD to fit the characteristics of EEP series.

The cumulative probability distribution $(F(x))$ of GPD is given as:

$F(x)=1-e^{-y}$ with

$y= \begin{cases}-\ln [1-k(x-\xi) / \alpha] / k & k \neq 0 \\ (x-\xi) / \alpha & k=0\end{cases}$

where $\xi, \alpha$, and $k$ is location, scale and shape parameter, respectively; $x$ is the independent variable and stands for the extreme precipitation series in this study. 

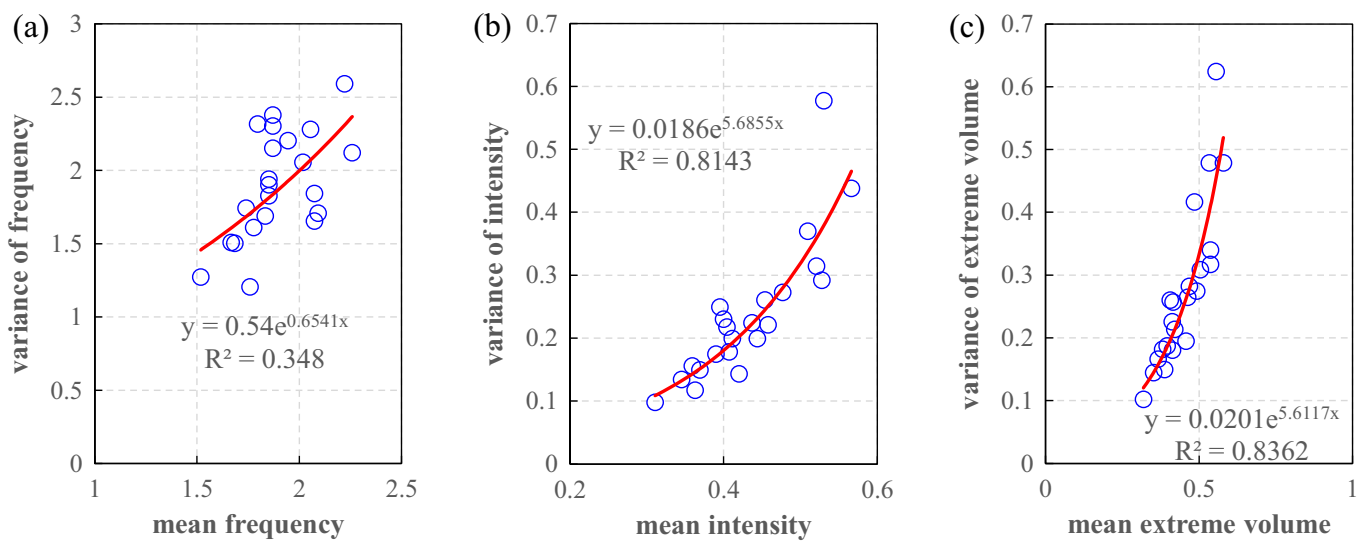

Fig. 5. The scatter diagram of mean and variance of (a) frequency, (b) intensity and (c) extreme volume at all stations over HJRB.

The return level $X_{T}$ under the return period of $T$ years can be given as:

$X_{T}= \begin{cases}\hat{\xi}+\frac{\hat{\alpha}}{\hat{k}}\left(1-(1 / T)^{\hat{k}}\right) & \hat{k} \neq 0 \\ \hat{\xi}-\hat{\alpha} \log (1-(1 / T)) & \hat{k}=0\end{cases}$

where $\hat{\xi}, \hat{\alpha}$, and $\hat{k}$ are the estimates of $\xi, \alpha$, and $k$, respectively, and can be estimated by the $L$-moment method (see the detail in the literature (Hosking, 1990; Hosking and Wallis, 1997; Xia et al., 2011)). The Kolmogorov-Smirnov (KS) method at the significance level of 0.05 is used as the goodness of fit test to check the efficiency of modelling.

\subsection{Moving window method}

In this study, the moving window method (Kao and Ganguly, 2011; Ghosh et al., 2012; Vittal et al., 2013) was considered to deal with the potential non-stationarity probably existing in the EP series. The method was implemented as follows. Assume that the entire extreme series is $\left\{y_{1}, y_{2}, \ldots, y_{N}\right\}$. Generally, the entire series was only fitted by one EVD. However, in the moving method, the $Y$-years moving window method applies the EVD fitting to the sub-series of $\left\{y_{i}, y_{i+1}, \ldots, y_{i+Y-1}\right\}(i=1, \ldots, N-Y+1) . Y$ is called as the moving window size. A choice of 30 years of window size, which was recommended by Kao and Ganguly (2011) considering that it was expected to smooth out the effects of most multidecadal climate oscillators and providing more confidence for low frequency extremes (Kharin et al., 2007), was also used in this study.

\section{Case study}

In order to demonstrate the key advantage of the proposed EEP concept, we apply the methods to Hanjiang River (HR) in China, one of the largest tributary of Yangtze River, located between 10 $6^{\circ} 15^{\prime} \mathrm{E}-114^{\circ} 20^{\prime} \mathrm{E}$ and $30^{\circ} 10^{\prime} \mathrm{N}-34^{\circ} 20^{\prime} \mathrm{N}$ with a length of $1570 \mathrm{~km}$ and basin area of about $159,000 \mathrm{~km}^{2}$ (Fig. 2) (Guo et al., 2009). It stretches $1577 \mathrm{~km}$ from Shaanxi to Hubei Provinces, returning Yangtze River in Wuhan City. The river passes through Gansu, Sichuan, Henan, and Chongqing Provinces in China (Fig. 2) (Xu et al., 2012). The elevation of the basin decreases from about $3495 \mathrm{~m}$ in the northwest to about $1 \mathrm{~m}$ in the southeast (Fig. 2). Danjiangkou Reservoir (see Fig. 2) on the upper reach of HJRB is the water source area of the central route of the South to North Water Diversion Project (SNWDP), which is considered as a strategic and ambitious approach to resolve the water shortage in northern China (Liu and Zheng, 2002) and is projected to divert 13 billion $\mathrm{m}^{3} \mathrm{yr}^{-1}$ of water to the North China Plain from 2014 (Liu et al., 2012; Sun et al., 2014). The Jianghan Plain in the lower reach of HJRB is one of the most important bases for commodity grain production.

The watershed of HJRB locates in the hydro-climatically sensitive region that serves as the natural boundary between the Temperate and Sub-tropical Zones in central China, and can been divided into three sub-basins: Upper reach of Danjiangkou, Tangbai River and Lower reach of Danjiangkou (see Fig. 2). The mean annual temperature of this area is about $14-16{ }^{\circ} \mathrm{C}$. The regional precipitation of URHR are characterized by high seasonal variability with the annual precipitation varying from $700 \mathrm{~mm}$ to 1100 , of which $70-80 \%$ occurs in rainy season (from May to October) (Guo et al., 2009).

In this study, daily precipitation data collected from 22 meteorological stations in HJRB are used to study the changes of EP in this area. The data were provided by China Meteorological Administration (CMA) and were believed to have high-quality. All of the stations were constructed before 1960. Therefore, in order to ensure that all the EEP events are analyzed during the same period, we consider only the period of 1960-2013 and exclude the earlier part of the data set from our analysis. All the used stations are showed in Fig. 2 and a summary is given in Table 1.

\section{Results and discussions}

In order to demonstrate the importance of EEP proposal in the case study, we will firstly show the spatial variation of the thresholds while extracting the EEP series using the percentile method and computing the characteristics of EEP events according to the definitions in Section 4.1, and then analyze the spatial and temporal changes of EEP events in Sections 4.2 and 4.3. Finally and importantly, we will also demonstrate the advantage of our proposed EEP concept in comparison with the traditional EP concept.

\subsection{Determination of EEP series}

In this study, the 97.5th percentile, which was used by Wang and Zhou (2005) to analyze the EP in China during 1961-2001, was employed to determine the EEP threshold. The threshold under the 97.5th percentile for individual stations were interpolated over the entire HJRB by the Kriging method to show its spatial variation (Fig. 3). The 97.5th percentile exhibited significant variability across space, emphasizing the importance of using local tolerance capacity in defining the threshold. Fig. 3 reveals an increasing trend on the thresholds from the southeast to the northwest of HJRB. The largest threshold was observed at WY station 

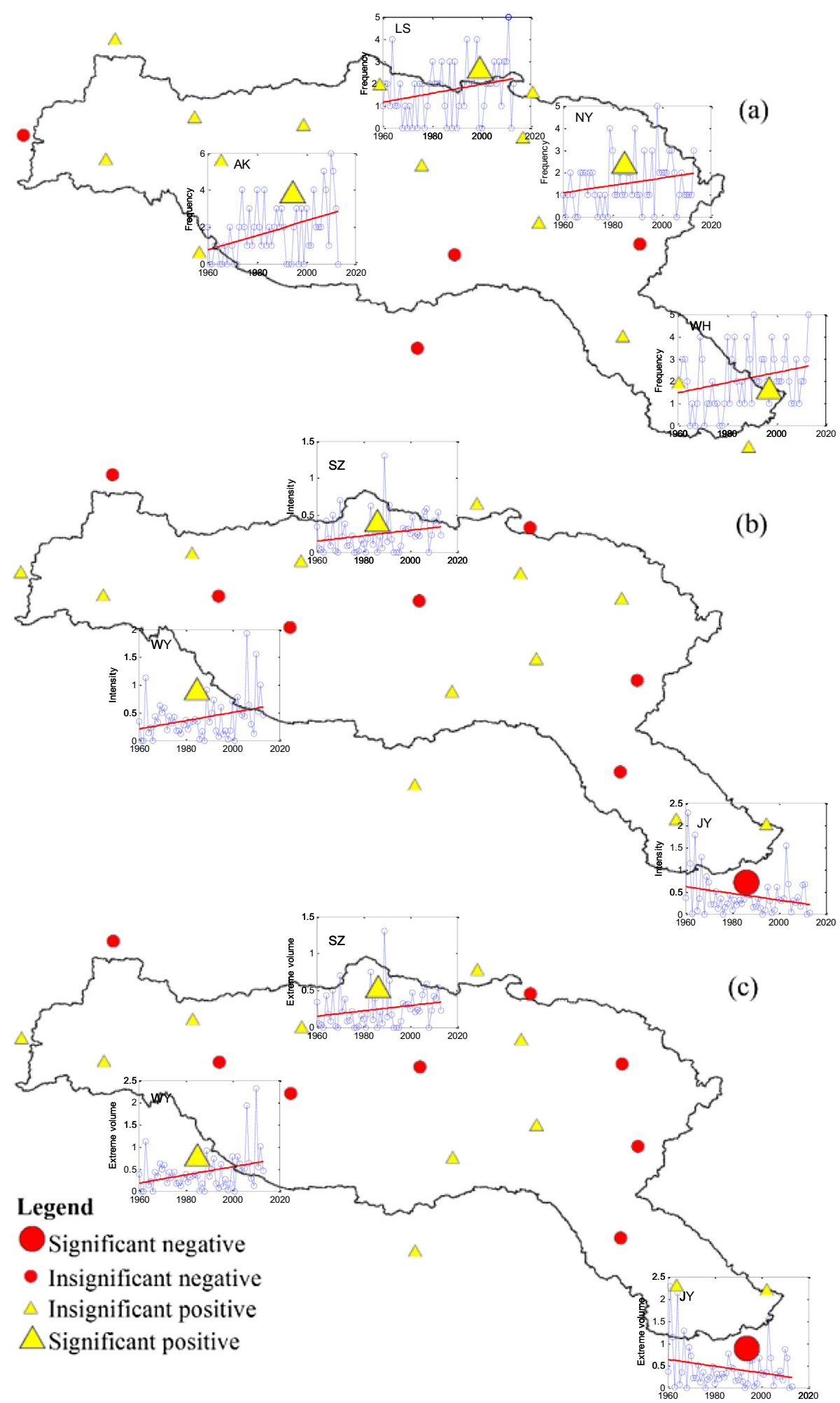

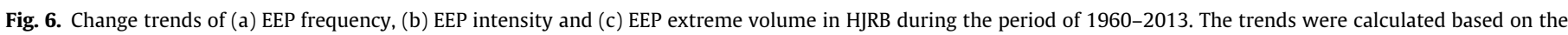
linear regression method. (Note: Temporal changes of each indicator were shown only in the stations with significant trends in each figure.)

with the value of $76.8 \mathrm{~mm}$, and the lowest one was at BJ station with the value of $39.3 \mathrm{~mm}$ (Fig. 3). It can also be observed that among the three sub-basins, the thresholds in the lower reach of Danjiangkou and Tangbai River were larger than that in the upper reach of Danjiangkou (Fig. 3). Furthermore, the different threshold values at the same percentile suggested that it might not be appropriate to choose a fixed precipitation amount as the threshold for all stations.

\subsection{Spatial variations of extreme precipitation characteristics}

The EEP series can be generated in each station by using the derived thresholds. Then, the frequency, intensity and extreme volume of EEP events were calculated in each station according to the definitions in Section 2.1 and summarized for the entire period in Fig. 4, from which it can be seen that the mean frequency in the southern part was slightly higher than that in the northern part 

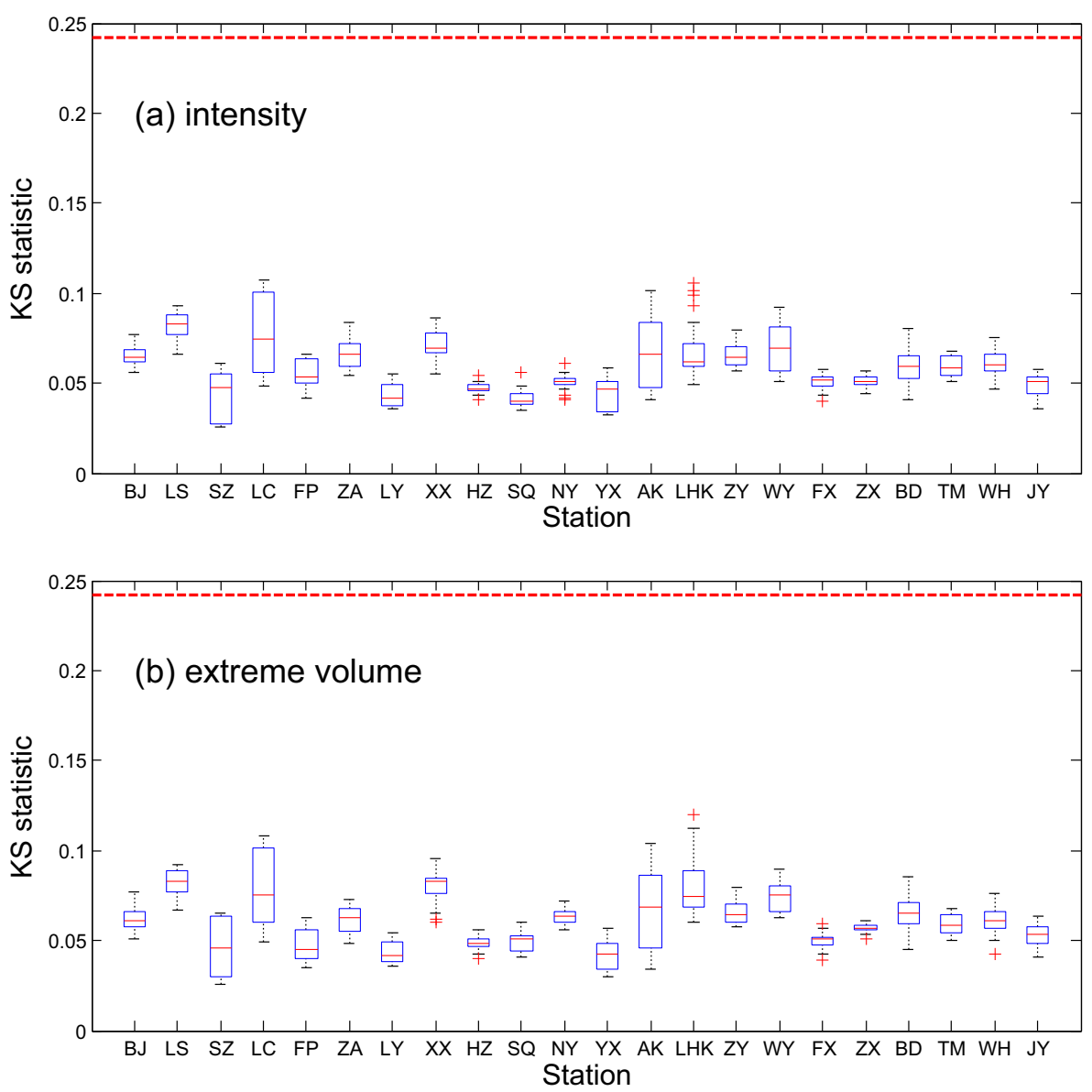

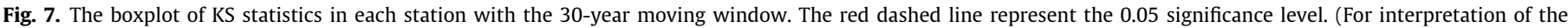
references to colour in this figure legend, the reader is referred to the web version of this article.)

of HJRB (Fig. 4(a)). The highest and lowest mean frequencies were 2.24 events/year and 1.5 events/year at JY (southernmost HJRB) and NY stations (northern HJRB), respectively (Fig. 4(a)). The boxplots illustrating the frequency variability associated with the 22 stations (Fig. 4(a)) showed that the highest frequency was 5 or 6 events/year in most stations except LY, ZX and BD stations which had the highest observed frequency of 7 events/year.

In contrast to frequency, both the intensity and extreme volume, as displayed in Fig. 4(b) and (c), exhibited irregular spatial variations. Both the largest and lowest intensity and extreme volume were observed at ZY and SZ station, respectively, with the intensity of 0.57 and 0.31 , and extreme volume of 0.58 and 0.32 , respectively. Similar to Fig. 4(a), the boxplots in Fig. 4(b) and (c) illustrated that the maximum intensity and extreme volume of EEP events were observed in YX station, with the intensity of 6.33, which means that the precipitation amount was about 6.33 times of the corresponding threshold $(46.5 \mathrm{~mm})$. This EEP event occurred in 18 July, 1997 with the precipitation amount of $327 \mathrm{~mm}$, has reported to result in large economic losses (about 0.25 billion RMB) in that area.

The variances of frequency, intensity and extreme volume series in each station and plotted against the averaged values in Fig. 5, from which positive correlations between the average and variance were observed for all the three variables, especially for intensity and extreme volume. This result was consistent with Fig. 4 which showed that a relative high medium value always corresponds to a relative large range between minimum and maximum values. It can be concluded that the higher the mean value was, the larger the variability would be in our study area.

\subsection{Temporal changes of extreme precipitation characteristics}

The trends of EEP frequency, intensity and extreme volume in 22 stations of the present study were given in Fig. 6 where the linear regression method was used to determine the significance of the trends during the entire period. The significance level of 0.05 was used. For the trends of EEP frequency (Fig. 6(a)), most stations (18 of 22 stations) exhibited an increasing trends with 4 of them was significant. Only 4 stations showed negative but insignificant trends. These results indicated an overall slightly increasing EEP frequency in HJRB. For the EEP intensity (Fig. 6(b)), 14 stations displayed increasing trends with 2 significant) and 8 stations displayed decreasing trends with 1 significant. The most stations with negative trends located in the middle part of HJRB. The changes of EEP extreme volume (Fig. 6(c)) were similar to that of EEP intensity. Therefore, it is necessary to take account of nonstationarity in the detailed analysis.

\subsection{Analysis of extreme precipitation series with consideration of non- stationarity}

\subsubsection{Changes of the parameters of extreme distribution}

To further evaluate the changes of intensities and extreme volumes, we employed the approach introduced by Kao and Ganguly (2011), Vittal et al. (2013), particularly, to fit the intensity and extreme volume series of EEP events extracted from each of the 30-year moving windows during 1960-2013 by GPD. In total, 25 GPDs would be obtained to model the extreme series with starting year from 1960 to 1984 in each station. The parameters of GPD 

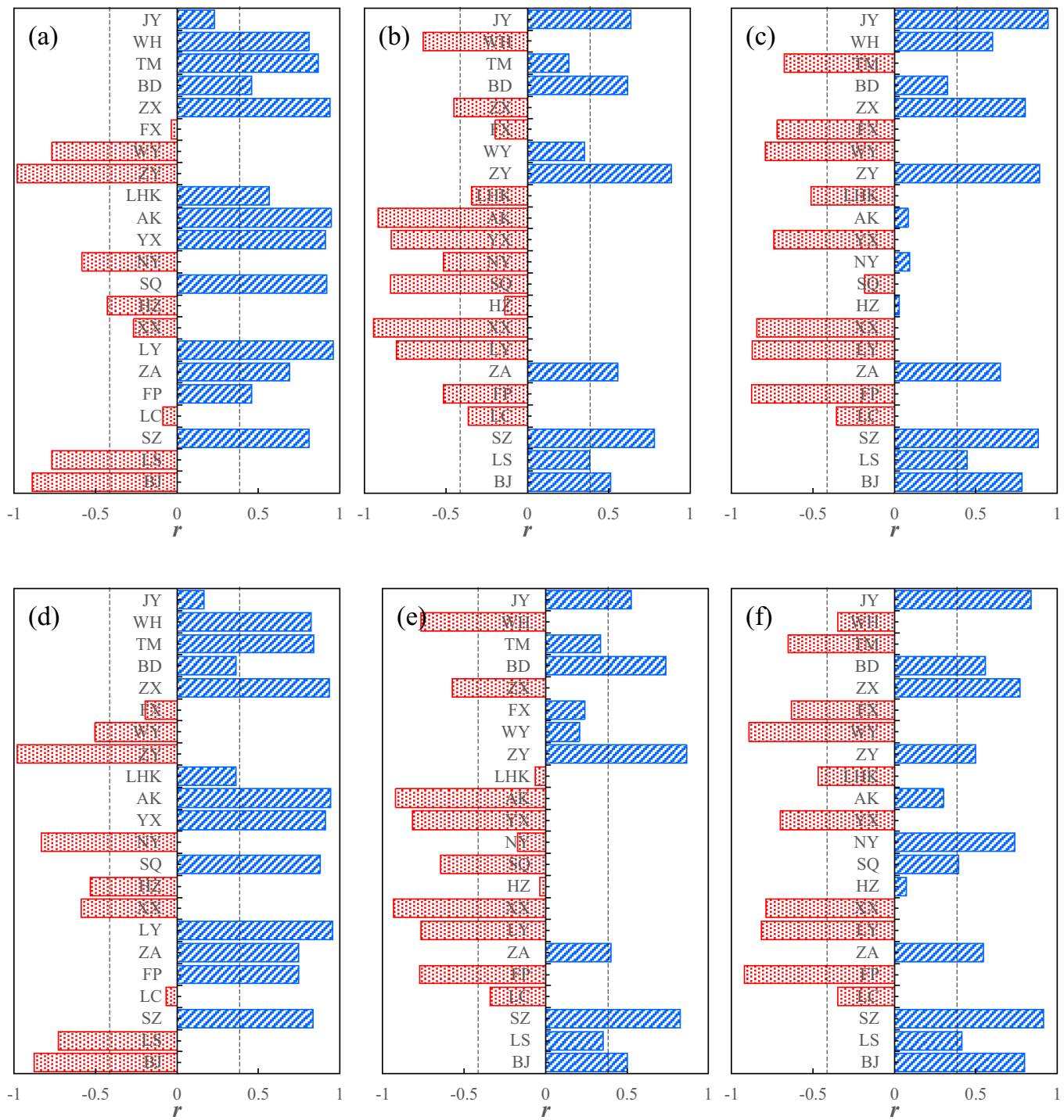

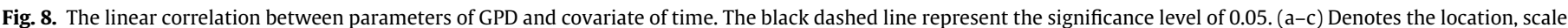

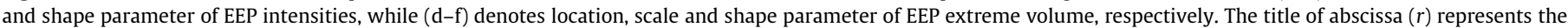
linear correlation coefficient.

were estimated by the L-moment method, and the goodness-of-fit was tested using the KS test. Fig. 7 showed the boxplots of the 25 KS statistic values in each station and also the critical value of 0.05 significance level. It can be seen that the maximum value of KS statistics in all stations for both intensity (Fig. 7(a)) and extreme volume series (Fig. 7(b)) were less than the critical value, suggesting that GPD can be used to model the EEP intensity and extreme volume of EEP events of all stations in HJRB.

Furthermore, the linear trends of location, scale and shape parameter of the 25 fitted GPDs in each station were examined by using their correlation with time (Fig. 8). It can be seen that at least one distributional parameter in both intensity and extreme volume fitting was significant at the level of 0.05 , except in LC station. However, the trends did not appear to follow a simple linear trend and no uniform functional form can describe the trends for all parameters. This can also be obtained upon visual inspection in Fig. 9, which depicted the parameter variation over time for a randomly selected station (LS station). Therefore, although the linear relationship between parameters and time have passed the statistical test in large proportion of stations, the linearity assumption did not seem to explain the real tendencies, supporting the reason that we did not use the time as a covariate to model the extreme series in this study. Similar conclusions can also be made for the extreme volume of EEP events in Figs. 8(d)-(f) and 9.

The GPD parameters provide some useful and meaningful information in understanding the changes of extreme events. The location parameter describes the central of distribution, the scale parameter controls the extent of distribution, and the shape parameter can determine the shape of distribution. As a result, the changes of the parameters can reflect the variations of EEP to some extent. According to Eq. (4), the return levels are determined by four factors: the return period $(T)$, location parameter, scale parameter and shape parameter. Under the same return period, the changing parameters can result in different return levels. As the parameters based on the 30-year moving window have changed over time, the return levels should also change over time. The detail trends of return levels will be analyzed in the next section.

4.4.2. Variations of return levels of extreme precipitation events

The corresponding 30 year return levels (i.e. $T$ in Eq. (4) is 30 years) in each of the 30 -year moving window periods were calculated to reveal the trends of EEP events in HJRB. 

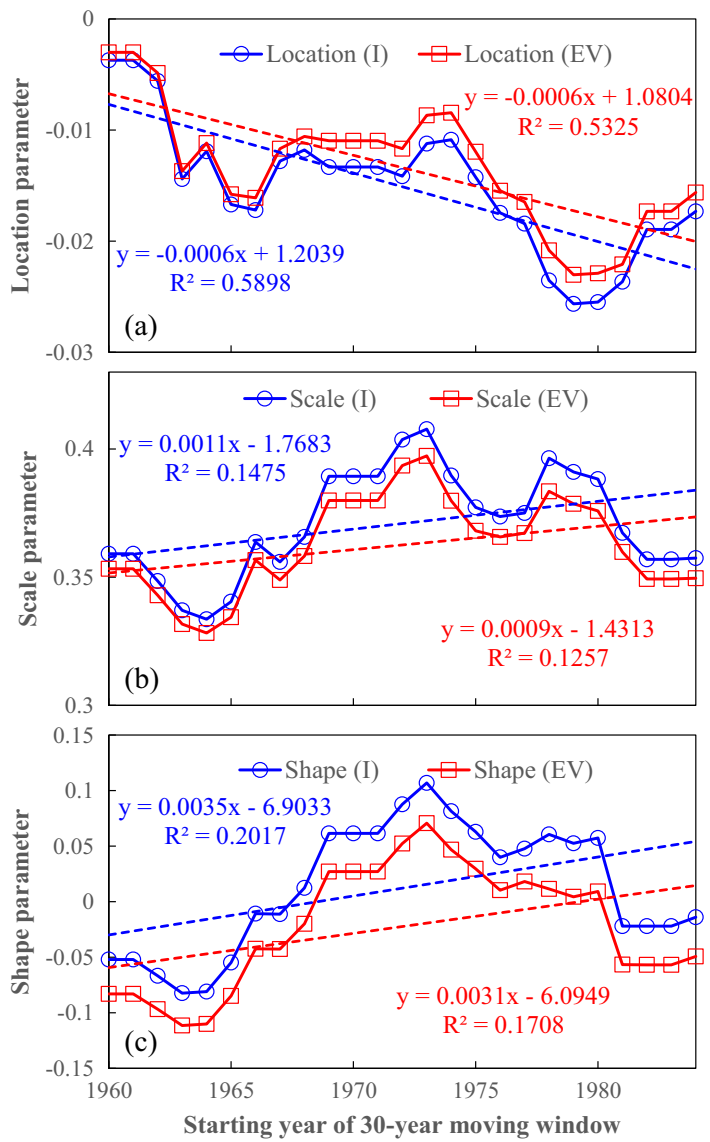

Fig. 9. Trends in the three GPD parameters at a randomly selected station (LS station in Fig. 1). The trends based on the parameters are calculated over each 30 year moving window.

As a preliminary result, the average of the 25 values from the 30 -year moving widow were calculated and then interpolated into the whole HJRB (Fig. 10). The spatial distribution of the average 30year return levels of EEP intensities (left part of Fig. 10(a)) exhibited an irregular variation, although it seemed that the mean return levels in the lower reach of Danjiangkou and Tangbai River were larger than that in the upper reach of Danjiangkou. The maximum mean value of 2.24 was observed in $\mathrm{ZY}$ station and the minimum of 1.12 was observed in SZ station (Figs. 10 and 11(a)). The boxplot of mean return levels of EEP intensities given in the right panel of Fig. 10(a) illustrated the intensity variability associated with the 22 stations of the present study. It can be seen that the variations of mean return levels of EP intensity was quite consistent with that of mean EEP intensity by viewing the scatter plot between these two series (see Fig. 11(a)). This can also be reflected by the visually comparisons of the spatial distributions from Figs. 4 (b) and $10(a)$.

The mean return levels of extreme volume of EEP events showed a similar spatial distribution with that of intensity, with an irregular spatial variation (Fig. 10(b)). It can also be seen that the mean values in the lower reaches of Danjiangkou and Tangbai River were larger than that in the upper reach of Danjiangkou, and a good coherence can also be observed between mean return levels and mean extreme volume upon visual inspection and linear correlation relationship given in Fig. 11(b).

In detail, the trends of the 25 values of 30-year return levels for EEP intensity were also plotted and evaluated by linear regression in each station (Fig. 12), from which it can be seen that 13 stations exhibited decreasing trends with 10 being significant and 9 stations exhibited increasing trends with 7 being significant. From the perspective of spatial variation, most areas in northwestern and southeastern part of HJRB showed negative trends, while some areas of central HJRB showed positive trends. In most stations, significant increasing or decreasing trends were presented with little fluctuation around the smoothing curves. However, in all the stations displaying nonsignificant trends and a few stations displaying significant trends, the curve seemed to exhibit an abrupt change around the year of 1973 . This phenomenon may indicate that the changes of EEP intensity around 1973 might be altered in these stations. The complex change of the return levels of EEP intensity would bring great challenges for the local water allocation and management.

The trends of return levels of EEP extreme volume were similar to that of EEP frequency (Fig. 13). The trends were negative in 12 stations and positive in the rest 10 stations, with 10 stations and 8 stations presenting significant negative or positive trends, respectively. The spatial variation was also similar with that of EEP intensity (see Fig. 12).

\subsection{Comparison with traditional extreme precipitation analysis method}

\subsubsection{Consideration of the temporal continuity of EP occurrence}

In order to test the influence of the continuity of EP occurrence in term of return levels, we selected two EEP events with EEP duration exceeding two days in two stations (BJ and WY stations) and computed the return period of EP characteristic using both the traditional method and the proposed EEP method in this study (Table 2). In BJ station, the EEP event occurred during 22 August, 1976 (with precipitation amount of $54.2 \mathrm{~mm}$ ) and 23 August, 1976 (with precipitation amount of $71.5 \mathrm{~mm}$ ). The EEP duration was two days in this event. Under the traditional method, this EEP event was divided as two separately single EPs with the intensity determined by the precipitation amount, while it was treated as one event with the intensity of 0.8193 and extreme volume of 1.1985 in the EEP method. Similar description can also be found in the station of WY (Table 2). The whole intensity and extreme volume series was also fitted by the GPD model and the KS test was employed as the goodness-of-fit measure. All of the extreme series in both traditional method and EEP method passed the KS test. The return periods of intensity and extreme volume were computed for all the selected EP events. In BJ station, the return periods of two separated EP events of traditional method were 2.78 and 8 years respectively, and 7.45 and 16.17 years for the intensity and extreme volume of EEP method respectively. However, the return period of extreme volume of EEP method was larger than that of intensity of traditional method. Similar results can also be seen in WY station. From these results, we can conclude that the EEP method with the consideration of continuity of EP occurrence had a larger return period, reflecting the continuity property of EP events, while the traditional method might eliminate the influence and consequence of consecutive EP with a smaller return period. We believe that the proposed EEP is closer to the common understanding of extremes because it manages the extremes on event basis.

\subsubsection{Consideration of local tolerance capacity}

We also demonstrated the advantage of considering the local tolerance capacity in the EEP method. The previous two stations in Section 4.5 .1 (i.e., BJ and WY) with largely different $97.5 \%$ threshold values were also used, two EP events with approximately precipitation amount were chosen (Table 3).

As the traditional EP method used the maximum precipitation amount to define the intensity, the values (i.e., $116.3 \mathrm{~mm}$ and $115.8 \mathrm{~mm}$, respectively) were very similar for the two EP events. 

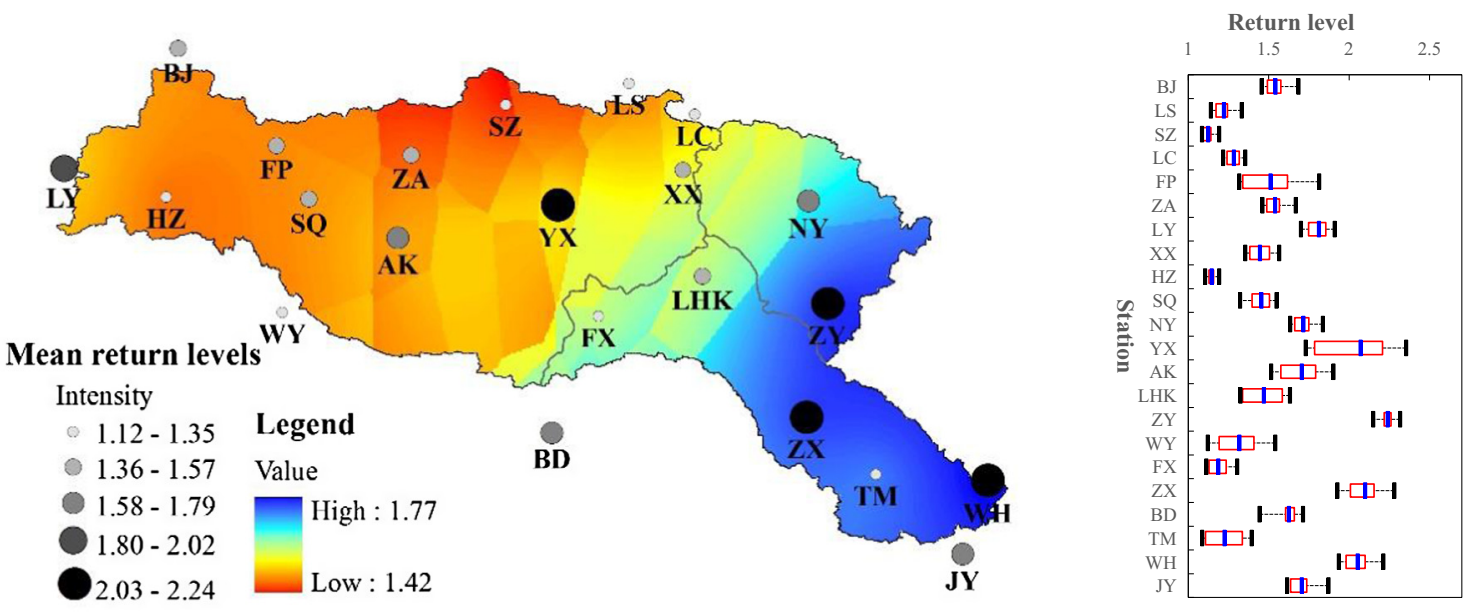

(a)
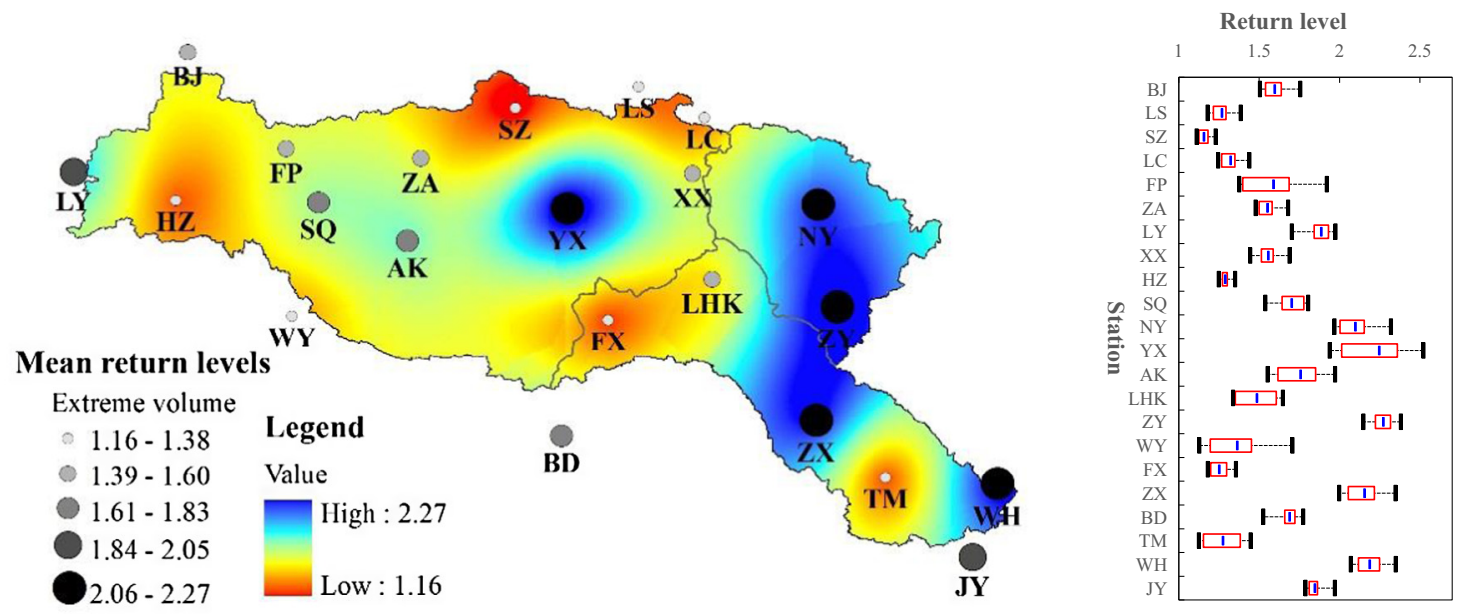

(b)

Fig. 10. The spatial distribution of the mean return precipitation in HJRB. The left and right part represent the spatial and temporal variation of the value respectively. The station is sorted by the latitude and the red line represent the linear regression curve between the mean return levels and latitude. (For interpretation of the references to colour in this figure legend, the reader is referred to the web version of this article.)
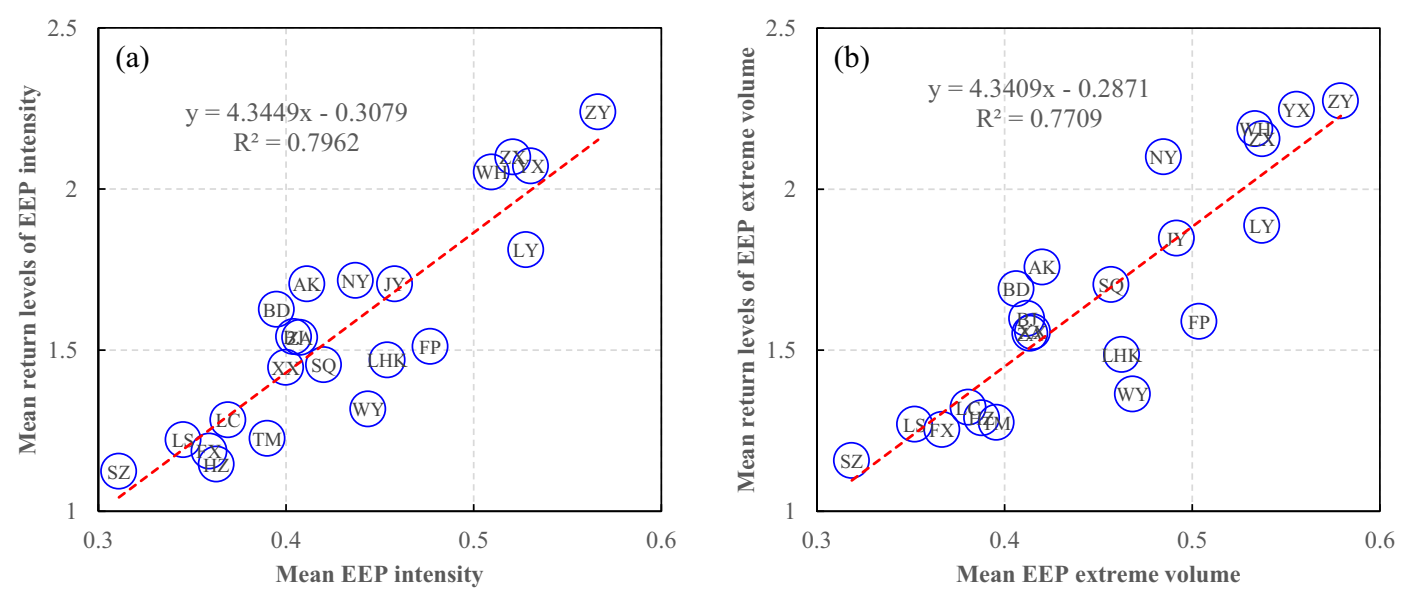

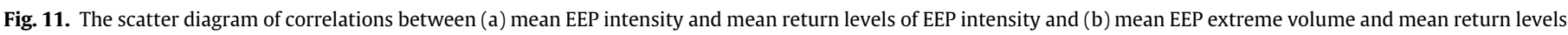

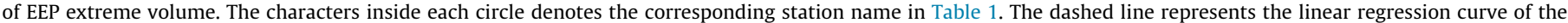
variables.

However, our proposed EEP method considered the different local tolerance capacities in different stations and defined the intensity by using the amount of the maximum precipitation above the threshold divided by the corresponding threshold, which were
1.9593 and 0.5087 , respectively, for the two events. We can see that the intensities in the EEP concept were largely differed. Furthermore, the precipitation amount of $116.3 \mathrm{~mm}$ in $\mathrm{BJ}$ station was much higher than its $97.5 \%$ threshold (196\% higher), while 


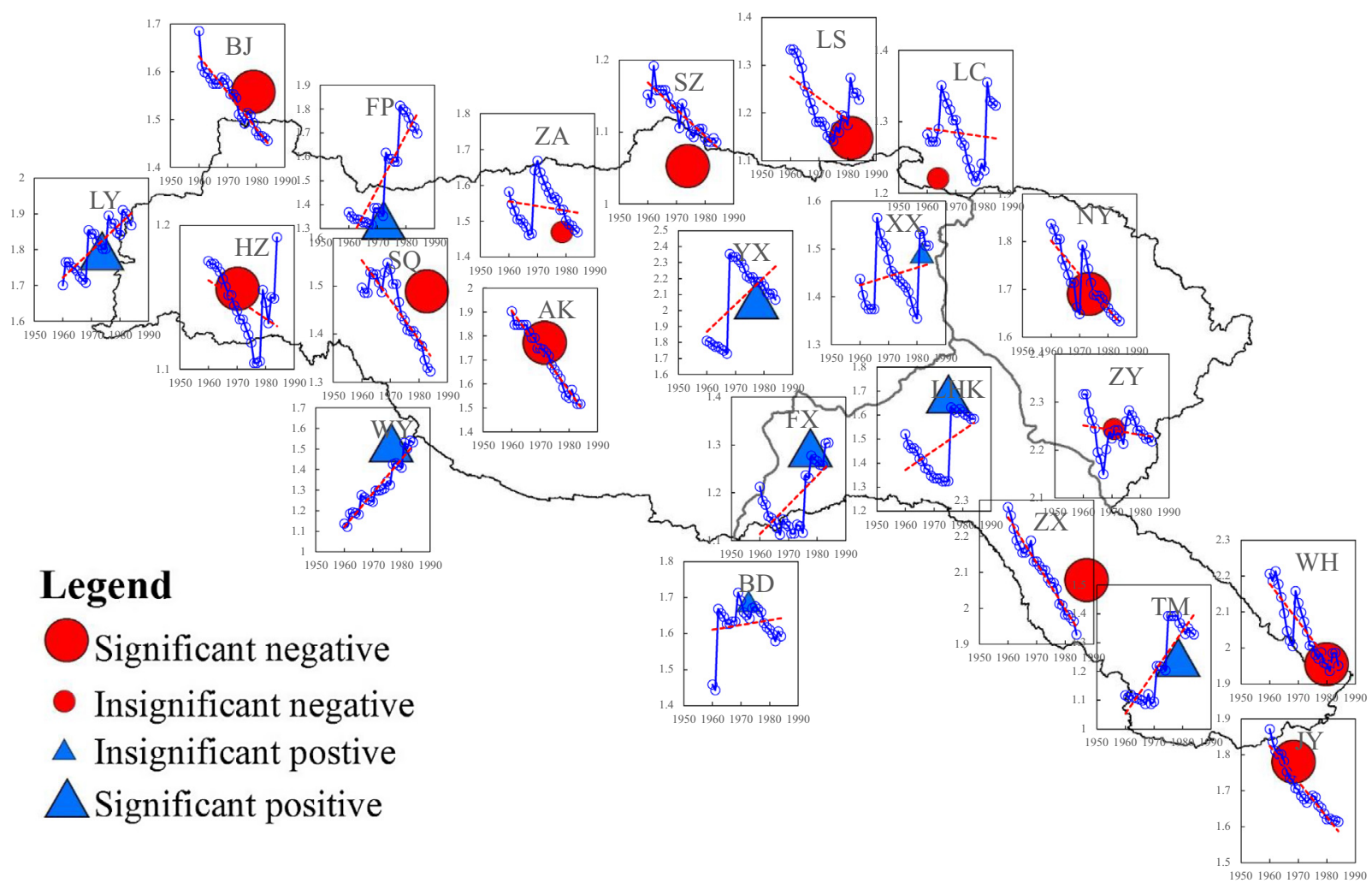

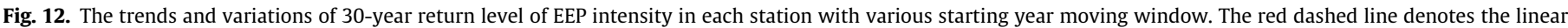
regression curve. (For interpretation of the references to colour in this figure legend, the reader is referred to the web version of this article.)

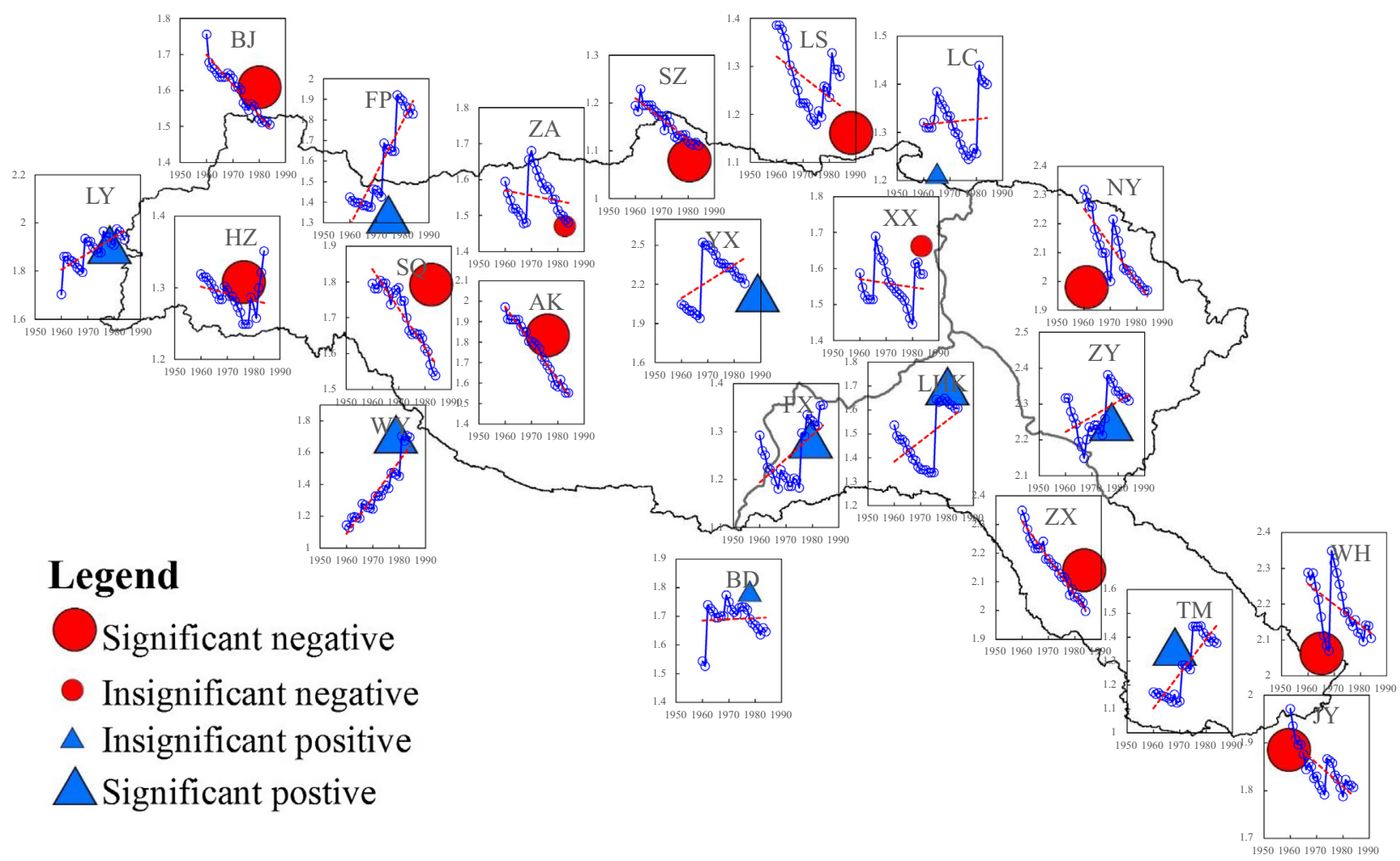

Fig. 13. The same with Fig. 12 but for extreme volume. 
Table 2

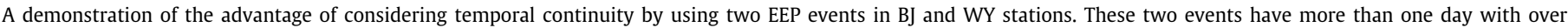

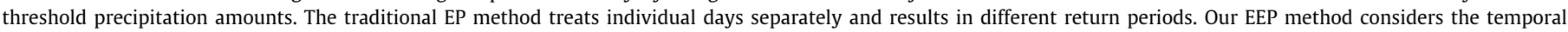
continuity and manages the extremes on event basis.

\begin{tabular}{|c|c|c|c|c|c|c|c|}
\hline \multirow[t]{2}{*}{ Station } & \multicolumn{3}{|l|}{ Traditional method } & \multicolumn{4}{|c|}{ EEP method } \\
\hline & Date & Intensity (mm) & Return period & Intensity & Return period of intensity & Extreme volume & Return period of extreme volume \\
\hline \multirow[t]{2}{*}{ BJ } & 22 August, 1976 & 54.2 & 2.78 & \multirow[t]{2}{*}{0.8193} & \multirow[t]{2}{*}{7.45} & \multirow[t]{2}{*}{1.1985} & \multirow[t]{2}{*}{16.17} \\
\hline & 23 August, 1976 & 71.5 & 8 & & & & \\
\hline \multirow[t]{3}{*}{ WY } & 31 August, 2003 & 90.1 & 1.58 & \multirow[t]{3}{*}{0.9766} & \multirow[t]{3}{*}{8.86} & \multirow[t]{3}{*}{1.2995} & \multirow[t]{3}{*}{14.71} \\
\hline & 1 September, 2003 & 151.8 & 9.69 & & & & \\
\hline & 2 September, 2003 & 88.3 & 1.49 & & & & \\
\hline
\end{tabular}

\section{Table 3}

A demonstration of the advantage of considering local tolerance capacity by using two precipitation events with similar amounts in BJ and WY stations. These two stations have largely different $97.5 \%$ threshold values. The traditional EP method uses the original precipitation amount and therefore cannot differentiate the different risk levels. However, our proposed EEP method can clearly differentiate the different risk levels by the EEP intensity defined by the amount of the maximum precipitation above the threshold divided by the corresponding threshold.

\begin{tabular}{|c|c|c|c|c|c|}
\hline \multirow[t]{2}{*}{ Station } & \multirow{2}{*}{$\begin{array}{l}\text { Threshold } \\
(\mathrm{mm})\end{array}$} & \multirow[t]{2}{*}{ Date } & \multirow{2}{*}{$\begin{array}{l}\text { Precipitation } \\
\text { amount } \\
(\mathrm{mm})\end{array}$} & \multicolumn{2}{|l|}{ Intensity } \\
\hline & & & & $\begin{array}{l}\text { Traditional } \\
\text { method }\end{array}$ & EEP \\
\hline BJ & 39.3 & $21 / 8 / 1981$ & 116.3 & 116.3 & 1.9593 \\
\hline WY & 76.8 & $16 / 8 / 1990$ & 115.8 & 115.8 & 0.5078 \\
\hline
\end{tabular}

the precipitation amount of $115.8 \mathrm{~mm}$ in WY station was only little higher than its $97.5 \%$ threshold (51\% higher), that is, at these similar precipitation amounts, BJ station was at much higher risk than WY station. However, the traditional EP method used the original precipitation amount and therefore cannot differentiate the different risk levels, while the intensities defined in our EEP method (1.9593 and 0.5078 for BJ and WY, respectively) can clearly reflect the different risk levels. Therefore, our proposed EEP method might be more appropriate than the traditional method.

\section{Summary}

In this study, we revisited the analysis of extreme precipitation (EP) and proposed the concept of event-based extreme precipitation (EEP) with the comprehensive consideration of both local tolerance capacity (i.e., threshold) and the temporal continuity of EP occurrence, and also defined several variables (i.e., duration, intensity and extreme volume) to describe the characteristics of EEP events. Our proposed EEP concept is suitable for both precipitation series at different time scales (e.g., hourly and daily). However, due to the difficult in the collection of long time continuous hourly precipitation data, we only applied this new proposal to the daily data to analyze the changes of EP in the Hanjiang River Basin of China (HJRB) with the consideration of non-stationarity in the extreme series.

For the case study, the 97.5th percentile is appropriate to determine the threshold in defining the extreme precipitation. The mean frequency of extreme event exhibited an obvious spatial variation with decreasing tendency from southeast to northwest direction. However, both the intensity and extreme volume had irregular spatial variations. To reveal the temporal variations, GDP was used to fit the characteristics within a 30 year moving window. It was found that the trends of parameter change were not linear. The variations of mean return levels of EEP intensity was quite consistent with that of mean EEP intensity, and the mean return levels in the lower of Danjiangkou and Tangbai River is larger than that in the upper of Danjiangkou.

By comparing our proposed EEP method with the traditional method using the case study, we can conclude that the EEP method can better reflect the comprehensive impact and consequence than the traditional method by considering local tolerance capacity (i.e., threshold) and the temporal continuity of EP occurrence. Further, our definition of EEP is closer to the common understanding of extremes because it manages the precipitation extremes on event basis, and is also more appropriate than the traditional method because of the consideration of local tolerance capacity and the temporal continuity of extreme precipitation event.

\section{Acknowledgements}

This study was supported by the National Natural Science Foundation of China (No. 41501030), China Postdoctoral Science Foundation (No. 2014M550405), the Fundamental Research Funds for the Central Universities (No. 2042014kf0033), the State Key Program of National Natural Science of China (No. 51339004) and the National Grand Science and Technology Special Project of Water Pollution Control and Improvement (No. 2014ZX07204006). This work was also supported by CSIRO Computational and Simulation Sciences FSP. The meteorological data used in this study were collected from the China Meteorological Administration (CMA), which is highly appreciated. We also thank Dr. Hongxing Zheng for his helpful comments during our internal review process. Cordial thanks are extended to the Editor and two anonymous referees for their valuable comments.

\section{References}

Alexander, L., Zhang, X., Peterson, T., Caesar, J., Gleason, B., Klein Tank, A., Haylock M., Collins, D., Trewin, B., Rahimzadeh, F., 2006. Global observed changes in daily climate extremes of temperature and precipitation. J. Geophys. Res.: Atmos. 111 (D5). http://dx.doi.org/10.1029/2005JD006290.

Ali, H., Mishra, V., Pai, D., 2014. Observed and projected urban extreme rainfall events in India. J. Geophys. Res.: Atmos. 119 (22), 12,621-612,641.

Beguería, S., 2005. Uncertainties in partial duration series modelling of extremes related to the choice of the threshold value. J. Hydrol. 303 (1), 215-230.

Beguería, S., Angulo-Martínez, M., Vicente-Serrano, S.M., López-Moreno, J.I., ElKenawy, A., 2011. Assessing trends in extreme precipitation events intensity and magnitude using non-stationary peaks-over-threshold analysis: a case study in northeast Spain from 1930 to 2006. Int. J. Climatol. 31 (14), 2102-2114.

Bhunya, P.K., Berndtsson, R., Jain, S.K., Kumar, R., 2013. Flood analysis using negative binomial and Generalized Pareto models in partial duration series (PDS). J. Hydrol. 497, 121-132.

Bell, J.L., Sloan, L.C., Snyder, M.A., 2004. Regional changes in extreme climatic events: a future climate scenario. J. Clim. 17 (1), 81-87.

Chen, H., Guo, S., Xu, C.-Y., Singh, V.P., 2007. Historical temporal trends of hydroclimatic variables and runoff response to climate variability and their relevance in water resource management in the Hanjiang basin. J. Hydrol. 344 (3), 171184.

Du, H., Wu, Z., Zong, S., Meng, X., Wang, L., 2013. Assessing the characteristics of extreme precipitation over northeast China using the multifractal detrended fluctuation analysis. J. Geophys. Res.: Atmos. 118 (12), 6165-6174.

Easterling, D.R., Meehl, G.A., Parmesan, C., Changnon, S.A., Karl, T.R., Mearns, L.O., 2000. Climate extremes: observations, modeling, and impacts. Science 289 (5487), 2068-2074.

El Adlouni, S, Ouarda, T. Zhang X, Roy, R., Bobée, B., 2007. Generalized maximum likelihood estimators for the nonstationary generalized extreme value model. Water Resour. Res. 43 (3), W03410. http://dx.doi.org/10.1029/2005WR004545.

Fu, G., Yu, J., Yu, X., Ouyang, R., Zhang, Y., Wang, P., Liu, W., Min, L., 2013. Temporal variation of extreme rainfall events in China, 1961-2009. J. Hydrol. 487, 48-59.

Gemmer, M., Fischer, T., Jiang, T., Su, B., Liu, L.L., 2011. Trends in precipitation extremes in the Zhujiang River basin, South China. J. Clim. 24 (3), 750-761. 
Ghosh, S., Das, D., Kao, S.-C., Ganguly, A.R., 2012. Lack of uniform trends but increasing spatial variability in observed Indian rainfall extremes. Nat. Climate Change 2 (2), 86-91.

Goswami, B.N., Venugopal, V., Sengupta, D., Madhusoodanan, M., Xavier, P.K., 2006. Increasing trend of extreme rain events over India in a warming environment. Science 314 (5804), 1442-1445.

Griffis, V.W., Stedinger, J.R., 2007. Log-Pearson Type 3 distribution and its application in flood frequency analysis. I: distribution characteristics. J. Hydrol. Eng. 12 (5), 482-491.

Guo, S., Guo, J., Zhang, J., Chen, H., 2009. VIC distributed hydrological model to predict climate change impact in the Hanjiang Basin. Sci. China Ser. E: Technol. Sci. 52 (11), 3234-3239.

Hosking, J.R.M., 1990. L-moments: analysis and estimation of distributions using linear combinations of order statistics. J. Roy. Stat. Soc.: Ser. B (Methodol.) 52 (1), 105-124.

Hosking, J.R.M., Wallis, J.R., 1997. Regional Frequency Analysis: An Approach based on L-Moments. Cambridge University Press.

Kao, S.C., Ganguly, A.R., 2011. Intensity, duration, and frequency of precipitation extremes under 21st-century warming scenarios. J. Geophys. Res.: Atmos. 116 (D16). http://dx.doi.org/10.1029/2010JD015529.

Khaliq, M., Ouarda, T., Ondo, J.-C., Gachon, P., Bobée, B., 2006. Frequency analysis of a sequence of dependent and/or non-stationary hydro-meteorological observations: a review. J. Hydrol. 329 (3), 534-552.

Kharin, V.V., Zwiers, F.W., 2005. Estimating extremes in transient climate change simulations. J. Clim. 18 (8), 1156-1173.

Kharin, V.V., Zwiers, F.W., Zhang, X., Hegerl, G.C., 2007. Changes in temperature and precipitation extremes in the IPCC ensemble of global coupled model simulations. J. Clim. 20 (8), 1419-1444.

Li, Z., Li, C., Xu, Z., Zhou, X., 2014. Frequency analysis of precipitation extremes in Heihe River basin based on generalized Pareto distribution. Stoch. Environ. Res. Risk Assess. 28, 1709-1721.

Liu, C., Zheng, H., 2002. South-to-north water transfer schemes for China. Int. J. Water Resour. Dev. 18 (3), 453-471.

Liu, X., Liu, C., Luo, Y., Zhang, M., Xia, J., 2012. Dramatic decrease in streamflow from the headwater source in the central route of China's water diversion project: climatic variation or human influence? J. Geophys. Res.: Atmos. 117 (D06113). http://dx.doi.org/10.1029/2011JD016879.

Martins, E.S., Stedinger, J.R., 2001. Historical information in a generalized maximum likelihood framework with partial duration and annual maximum series. Water Resour. Res. 37 (10), 2559-2567.

Mishra, V., Dominguez, F., Lettenmaier, D.P., 2012. Urban precipitation extremes: how reliable are regional climate models? Geophys. Res. Lett. 39 (3), L03407. http://dx.doi.org/10.1029/2011GL050658.

Moberg, A., Jones, P.D., 2005. Trends in indices for extremes in daily temperature and precipitation in central and western Europe, 1901-99. Int. J. Climatol. 25 (9), 1149-1171.

Naveau, P., Toreti, A., Smith, I., Xoplaki, E., 2014. A fast nonparametric spatiotemporal regression scheme for generalized Pareto distributed heavy precipitation. Water Resour. Res. 50 (5), 4011-4017.

Pickands III, J., 1975. Statistical inference using extreme order statistics. Ann. Stat., $119-131$

Rajah, K., O'Leary, T., Turner, A., Petrakis, G., Leonard, M., Westra, S., 2014. Changes to the temporal distribution of daily precipitation. Geophys. Res. Lett. 41 (24), 8887-8894.
Ren, L., Yin, S., Jin, J., 2014. Variation and regional difference of annual precipitation in the upper reaches of Hanjiang River During 1960-2011. Chin. J. Agrometeorol. 35 (4), 365-372 (in Chinese).

Shao, Q., Wong, H., Xia, J., Ip, W.-C., 2004. Models for extremes using the extended three-parameter Burr XII system with application to flood frequency analysis. Hydrol. Sci. J. 49 (4), 685-702.

Stocker, T.F., Qin, D., Plattner, G.-K., Tignor, M., Allen, S.K., Boschung, J., Nauels, A., Xia, Y., Bex, V., \& Midgley, P.M., 2013. Climate change 2013. The Physical Science Basis. Working Group I Contribution to the Fifth Assessment Report of the Intergovernmental Panel on Climate Change-Abstract for Decision-Makers: Groupe d'experts intergouvernemental sur l'evolution du climat/ Intergovernmental Panel on Climate Change-IPCC, C/O World Meteorological Organization, 7bis Avenue de la Paix, CP 2300 CH-1211 Geneva 2 (Switzerland).

Sun, Y., Tian, F., Yang, L., Hu, H., 2014. Exploring the spatial variability of contributions from climate variation and change in catchment properties to streamflow decrease in a mesoscale basin by three different methods. J. Hydrol 508, 170-180.

Towler, E., Rajagopalan, B., Gilleland, E., Summers, R.S., Yates, D., Katz, R.W., 2010 Modeling hydrologic and water quality extremes in a changing climate: a statistical approach based on extreme value theory. Water Resour. Res. 46 (11). http://dx.doi.org/10.1029/2009WR008876.

Villarini, G., Smith, J.A., Napolitano, F., 2010. Nonstationary modeling of a long record of rainfall and temperature over Rome. Adv. Water Resour. 33 (10), 1256-1267.

Vittal, H., Karmakar, S., Ghosh, S., 2013. Diametric changes in trends and patterns of extreme rainfall over India from pre-1950 to post-1950. Geophys. Res. Lett. 40 (12), 3253-3258.

Wang, W., Shao, Q., Yang, T., Peng, S., Yu, Z., Taylor, J., Xing, W., Zhao, C., Sun, F. 2013. Changes in daily temperature and precipitation extremes in the Yellow River Basin, China. Stoch. Environ. Res. Risk Assess. 27 (2), 401-421.

Wang, Y., Zhou, L., 2005. Observed trends in extreme precipitation events in China during 1961-2001 and the associated changes in large-scale circulation. Geophys. Res. Lett. 32 (9), L09707. http://dx.doi.org/10.1029/2005GL022574.

Xia, J., She, D.X., Zhang, Y.Y., Du, H., 2011. Spatio-temporal trend and statistical distribution of extreme precipitation events in Huaihe River Basin during 1960 2009. J. Geograph. Sci. 22 (2), 195-208.

Xu, Y.-P., Yu, C., Zhang, X., Zhang, Q., Xu, X., 2012. Design rainfall depth estimation through two regional frequency analysis methods in Hanjiang River Basin, China. Theor. Appl. Climatol. 107 (3-4), 563-578.

Yang, T., Shao, Q., Hao, Z.-C., Chen, X., Zhang, Z., Xu, C.-Y., Sun, L., 2010. Regional frequency analysis and spatio-temporal pattern characterization of rainfall extremes in the Pearl River Basin, China. J. Hydrol. 380 (3), 386-405.

Zhai, P., Zhang, X., Wan, H., Pan, X., 2005. Trends in total precipitation and frequency of daily precipitation extremes over China. J. Clim. 18 (7), 1096-1108.

Zhang, H.G., Wang, H., Xu, D., Lv, S.Y., Zou, N., 2007. Changing tendency of water resources for upper Hanjiang River. J. Yangtze River Sci. Res. Inst. 24 (5), 27-30 (in Chinese).

Zhang, Q., Singh, V.P., Li, J., Jiang, F., Bai, Y., 2012. Spatio-temporal variations of precipitation extremes in Xinjiang, China. J. Hydrol. 434, 7-18.

Zhang, Y., Xu, Y., Dong, W., Cao, L., Sparrow, M., 2006. A future climate scenario of regional changes in extreme climate events over China using the PRECIS climate model. Geophys. Res. Lett. 33 (24). http://dx.doi.org/10.1029/2006GL027229. 